\section{Parental upset associated with partici- pation in induction of anaesthesia in children}

Judith A. Vessey PhD RNC, * Martin S. Bogetz MD $\dagger$ Catherine L. Caserza ms Rn, $\nmid$ Katrina R. Liu BA, $\uparrow$ Mary D. Cassidy BSN RN $\dagger$
To evaluate the magnitude of parental upset associated with participation in induction of anaesthesia in their child, we determined: (1) the features of induction most upsetting to parents; (2) the characteristics of parents most likely to become upset; and (3) the accuracy of the anaesthetist's perception of the magnitude of parental upset. The parents (101 mothers and $43 \mathrm{fa}$ thers) of 103 children scheduled for elective outpatient surgery requiring general anaesthesia with induction by mask were asked on admission to participate in this study. Parents and children were educated about anaesthesia and surgery according to unit protocols. Immediately afier induction of anaesthesia, the parents were asked to complete a demographic information sheet and the Parental Reactions to Anesthesia Induction Quessionnaire. Responses were analyzed using descriptive statistics and content analysis. The most upsetting factors for both mothers and fathers in order of significance were: (I) separation from the child after induction of anaesthesia; (2) watching/feeling the child go limp during induction; and (3) seeing the child

\section{Key words}

ANAESTHESIA: paediatric, outpatient; ANAESTHETIC TECHNIQUES: induction.

From the University of Arkansas for Medical Sciences and Arkansas Children's Hospital, Little Rock, Arkansas*, and the Department of Anesthesia and the UCSF Surgery Center, University of California, San Francisco, San Francisco, California. $†$

Originally prepared for presentation in part, at the International Anesthesia Research Society's Annual Meeting, San Antonio, Texas, March, 1991.

Address correspondence to: Dr. Vessey: Center for Applied Research and Evaluation, Arkansas Children's Hospital, 800 Marshall Street, Little Rock, AR 72202-3591.

Supported, in part, by the Robert Wood Johnson Clinical Nurse Scholars' Program.

Accepted for publication 5 th December, 1993. upset before induction. Characteristics of parents most likely to become upset revealed positive correlations between the amount of upset between mothers and fathers, mothers of an only child, and mothers or fathers who were health care workers $(P<0.05)$. The anaesthetist's perception of upset correlated with matemal $(P<0.05)$, but not parental, self-assessment of upset. We conclude that selected factors of parental participation are upsetting for the parents and that recognizing the factors associated with parental upset may enable operating room personnel to minimize these negative consequences.

Pour évaluer limportance de langoisse des parents associée à leur participation à l'induction de l'anesthésie de leur enfant, nous avons déterminé: 1) les aspects de l'induction les pius angoissants pour les parents; 2) les caractéristiques des parents les plus susceptibles dềtre perturbés; 3) la justesse de la perception par l'anesthésiste de limportance de langoisse parentale. Au moment de l'admission, nous avons sollicité la participation des parents (101 mères et 43 pères) de 103 enfants programmés pour une chirurgie ambulatoire sous anesthésie générale avec induction au masque. Nous avons renseigné les parents et les enfants sur l'anesthésie et la chinurgie conformément aux protocoles en usage. Immédiatement après l'induction de lanesthésie, nous avons demandé aux parents de remplir une formule de données démographiques et un questionnaire sur leurs réactions à l'induction de l'anesthésiste. Les réponses furent analysées par statistiques descriptives et analyse de contenu. Par ordre dimportance, les facteurs les plus angoissants pour les parents sont les suivants: 1) leur séparation de l'enfant après linduction; 2) la flaccidité de l'enfant pendant Iinduction; et 3) langoisse de lenfant avant linduction. Les caractéristiques des parents les plus szsceptibles dêtre perturbés révélent des corrélations positives entre limpontance des perturbations entre les mères et les pères, les mères d'enfants uniques, et les mères ou les pères travaillant dans le secteur de la santé $(P<0,05)$. La perception par l'anesthésiste de l'angoisse parentale corrélai bien avec l'auto-évahuation maternelle $(P<0,05)$ mais non avec l'auto-evaluation patemelle. Nous concluons que certains facteurs de la participation des parents sont angoissants et que ta connaissance de ces facteurs permettra au personnel des salles d'opération d'en minimiser les conséquences négatives. 
Parental presence during a child's anaesthetic induction is receiving increased attention by both professional and public personnel. Among hospitals with major paediatric services, approximately $15 \%$ now permit parents to accompany their children through anaesthetic induction, a two-fold increase in seven years. ${ }^{1}$ However, scientific data supporting the efficacy of parental participation are limited. ${ }^{2-4}$ Some studies suggest that children demonstrate less upset during induction ${ }^{3}$ and exhibit fewer behavioural problems ${ }^{2,3}$ when parents are present. Others do not support this view and suggest that parental presence may be detrimental in selected groups. ${ }^{5,6}$ Parents view their presence as benefiting the child and easing the task of the anaesthetist. $4,7-9$ Whether parents' emotional wellbeing suffers from participation is unclear. Research in areas such as paternal participation in childbirth ${ }^{10,11}$ suggests that the experience can be emotionally upsetting. Participation in the induction of anaesthesia, which is inherently more frightening (i.e., when the anaesthetized child appears dead), may be equally or more detrimental for some parents. Clinical observation supports this impression, even in parents who have been educated by hospital staff about what to expect. Few actually cry or faint, but many are visibly upset following participation in their child's induction. In the present study, we (1) determined the features of anaesthetic induction most upsetting to parents; (2) identified characteristics of parents most likely to become upset; and (3) correlated the anaesthetist's perception of parental upset with parental self-assessment.

\section{Methods}

Approval was obtained from the University of California, San Francisco Human Rights Committee for the study. The biological or adoptive parents of 103 children (ASA PS 1, 2, or 3) who were consecutively scheduled for elective outpatient surgery or procedures requiring general anaesthesia with induction by mask were asked to participate in the study. Informed consent was collected from the parents of all the children, yielding a $100 \%$ participation rate. All parents were literate in English. Parents were surveyed immediately following their participation in induction of anaesthesia in their child.

Parents and children were educated in a similar fashion about anaesthesia and surgery by either a resident or faculty anaesthetist in an attempt to help them become emotionally ready for the experience. For children, this included a tour of the outpatient facility, an appropriate discussion of the induction and recovery process, and a period of play with a "flavoured" anaesthesia mask of their choice. Many children also practised breathing through the anaesthesia circuit and "blowing up the balloon" (i.e., inflating and deflating the reservoir bag). Education for parents included a thorough discussion of an- aesthetic procedures and risks. Parents were also given a complete description of what to expect during induction of anaesthesia, and instructions regarding appropriate ways of comforting their child during induction.

On the day of the procedure, children and parent(s) were escorted to an induction room. Children were not premedicated, and efforts were made to keep the event from being unduly stressful. The child was given the option to lie down, sit next to, or on, the parent's lap. Anaesthesia was induced by inhalation of $70 \%$ nitrous oxide in oxygen, then of increasing concentrations of halothane. When a surgical plane of anaesthesia was achieved, parents were reassured that their child was alright, then escorted from the induction room to the Surgery Center waiting room, where they were immediately asked to complete a demographic information sheet and the Parental reactions to Anesthesia Induction Questionnaire (PRAIQ).

The demographic information sheet included information about family composition (siblings, primary caretaker, single parent home), socioeconomic status (employment status and educational level of parent[s]), ethnicity, and previous experience in witnessing an anaesthetic induction. The PRAIQ consisted of 15 items developed to measure parental self-assessment of their response to participating in their child's anaesthetic induction. These items, derived from the literature and staff interviews, were classified into four categories likely to cause parental distress: (1) the child's behaviour; (2) their own behaviour; (3) Surgery Center staff reactions; and (4) environmental factors (Table I). Parents were asked to rank each item using a 5-point scale where $0=$ no upset and $4=$ severe upset. Because some items (i.e., being reunited with your ex-spouse) were not relevant for some subjects, a "not applicable" response was also included. Both the written instructions and the survey questions were carefully worded to acknowledge the positive aspect of parental participation while permitting parents to express any degree of upset. The PRAIQ's overall instructions read: "For most parents, staying with their child through anaesthesia induction is a positive experience. There are certain aspects of the experience, however, that some parents have found upsetting. In an effort to improve the care we provide for you and your child, how upsetting did you find each of the following?" Also included in the PRAIQ were two open-ended statement/questions: (1) "Please describe anything else you found upsetting." and (2) "What could the Surgery Center staff do to make this a better experience?"

To determine the accuracy of the anaesthetist's perception of parental participation and upset, the anaesthetist completed a short questionnaire as soon as possible after induction. Using a 5-point scale the anaesthetist was 
TABLE I Percent of parents expressing upset following participation in induction

\begin{tabular}{lrr}
\hline & $\begin{array}{c}\text { Mother } \\
\%(n)^{*}\end{array}$ & \multicolumn{1}{c}{$\begin{array}{r}\text { Fother } \\
\%(n)^{*}\end{array}$} \\
\hline Upserting items & & \\
Child behaviour & $60.4(91)$ & $65.1(43)$ \\
Child going limp & $58.7(63)$ & $64.0(25)$ \\
Child being upset & & \\
Parental behoviour & $68.5(89)$ & $70.0(40)$ \\
Leaving the child & $31.3(55)$ & $45.8(24)$ \\
Reminders of previous experiences & $22.1(77)$ & $47.2(36)$ \\
Not knowing what to do after induction & $12.5(16)$ & $12.5(8)$ \\
Being reunited with ex-spouse & & \\
& & \\
Staff actions & $20.8(48)$ & $26.1(23)$ \\
Impatience with child & $14.8(27)$ & $15.4(13)$ \\
Rude behaviour & $9.9(71)$ & $6.3(32)$ \\
Lighthearted attitude & $9.8(41)$ & $31.6(19)$ \\
Impersonal attitude & & \\
& & \\
Environmental factors & $25.0(64)$ & $32.3(31)$ \\
Rushed induction & $17.2(87)$ & $11.9(42)$ \\
OR equipment & $3.5(86)$ & $19.5(41)$ \\
Amount of activity & $4.8(83)$ & $7.3(41)$ \\
Bright lights in OR & $7.6(79)$ & $16.2(37)$ \\
Noises from the OR & & \\
\hline
\end{tabular}

$*(n)=$ number of respondents for this item; number varies by item and does not include N/A (not applicable) responses.

asked to describe his or her perception of how upset each parent was $(0=$ no upset and $4=$ severe upset). Using a similar 5-point scale the anaesthetist was also asked to describe the degree of each parent's participation ( 0 $=$ active involvement and $4=$ no involvement).

Data were analyzed using descriptive statistics including measures of central tendency, frequencies, and Pearson $r$ correlation indices. A value of $P<0.05$ defined a significant relationship. The open-ended questions of the PRAIQ were analyzed using content analysis to identify common themes.

\section{Results}

The child sample included 39 girls and 64 boys who ranged in age from 8 mo to $11 \mathrm{yr}$ (mean $=5 \mathrm{yr}, 11$ $\mathrm{mo} ; \mathrm{SD}=2 \mathrm{yr}, 5 \mathrm{mo})$. All underwent elective outpatient surgery $(\mathrm{GU}=28 \%$, ENT $=25 \%$, eye $=14 \%$, other $=18 \%$ ) or non-operative procedures $(15 \%)$ requiring general anaesthesia. Thirty-one percent of the children came from single parent homes.

The parent sample included 101 mothers and $43 \mathrm{fa}-$ thers. Both parents were present for the surgery of 41 of the children; two children were accompanied only by their fathers, 60 were accompanied only by their mothers. The racial/ethnic background of the parents was $72 \%$ white, $10 \%$ black, $6 \%$ Hispanic, $5 \%$ Asian, and $7 \%$ "other." The parents were well-educated, with all par-
TABLE II Pearson's $r$ correlations: relationships among key variables and mothers' and fathers' self-report

\begin{tabular}{lll}
\hline & \multicolumn{2}{c}{ Self-report of upset } \\
\cline { 2 - 3 } Components of correlation & Mother & Father \\
\hline Anaesthetist's perception of maternal upset & $0.38^{*}$ & - \\
Anaesthetist's perception of maternal & & \\
participation & -0.07 & - \\
Anaesthetist's perception of paternal upset & - & 0.20 \\
Anaesthetist's perception of paternal & & \\
participation & - & 0.18 \\
$\begin{array}{l}\text { Only child } \\
\text { Mother employed in health care }\end{array}$ & $0.50 \dagger$ & 0.25 \\
Father employed in health care & $0.42^{*}$ & - \\
Father's self-report of upset & - & $0.40^{*}$ \\
\hline$* P<0.05$. & $0.36^{*}$ & - \\
\hline$P<0.01,2$-tailcd values. & & \\
\end{tabular}

ticipants having completed high school and $16 \%$ of mothers and $23 \%$ of fathers holding a graduate degree. A disproportionate number $($ mothers $=23 \%$, fathers $=18 \%$ ) were employed in some aspect of health care, but not necessarily in professional positions.*

Overall, $91 \%$ of mothers and $93 \%$ of fathers reported some degree of upset regarding at least one item on the PRAIQ (Table I). Mothers reported a higher degree of upset than fathers $(\mathrm{P}<0.05)$. The magnitude of upset was greatest for mothers who had only one child $(34 \%$ of children), followed by parents who were employed in health care ( $23 \%$ of mothers, $18 \%$ of fathers), and between husbands' and wives' reported upset (40\%) (Table II). In order of significance, the most upsetting factors were: (1) separation from the child after induction; (2) seeing and feeling the child go limp during induction; (3) witnessing the child's distress prior to induction; and (4) being reminded of past negative experiences (Table I). For a small number of couples, views of their child's induction experiences differed substantially. One extreme example was that of a mother who read a copy of a magazine during the child's induction, while the father stated he re-experienced watching his own mother die. The anaesthetist's perception of parental upset only correlated with maternal self-assessment (Table II).

Content analysis $\dagger$ of responses $(n=47)$ to the open-

* Many employees at UCSF participate in the universitymanaged health care system, accounting for these high numbers. †A procedure for analyzing written communications systematically and objectively so nominal variables may be identified and quantified. For further information, please see:

Krippendorff $K$. Content Analysis - An introduction to its methodology. Newbury Park, CA: Sage Publications, Inc., 1980. 
TABLE III Typical parental responses to the open-ended survey questions

Sense of helplessness: nine responses

Mother: "A feeling of helplessness and tremendous concern for my child's well-being."

Father: "I think it would be a good idea to give parents suggestions of what they could do."

Lack of support: six responses

Mother: "I needed to have an adult with me to support me and I didn't have one."

\section{Lass of controt: fourteen responses}

Mother: "Waiting in the waiting room and not having someone come out expressly to tell me how things were going. Although I know chances are very remote, if my child coded I would like to be called back to help."

Father: "It would be heipful to know how fast the induction was."

ended questions identified three common themes: a sense of helplessness, lack of psychological support, and loss of control (i.e., leaving after induction, not permitted to watch the procedure) (Table III). The sense of helplessness appeared to occur most often in fathers who were less actively involved than mothers in comforting the child during induction. These qualitative data were further confirmed by comparing the anaesthetist's impression of the degree of parental participation for the five fathers who indicated a sense of helplessness. Of these five fathers, three were evaluated by the anaesthetist on the 5-point scale as completely uninyolved (score $=4$ ) and two as moderately uninvolved (score $=3$ ). Four of the six parents who indicated a lack of support were single and 11 of the 14 parents who indicated a loss of control were health care workers. One auxiliary finding of interest was that $40 \%$ of parents fasted with their children and $24 \%$ had only coffee before their child's induction.*

There was no correlation between the magnitude of parental upset and parental educational level, the child's age, or parental previous experience(s) of participation in anaesthetic induction. The anaesthetist's appraisal of parental upset correlated poorly with patemal selfassessment (Table II).

\section{Discussion}

Although parental presence during a child's anaesthetic induction is promoted as an excellent way to improve a child's cooperation and reduce the anxiety and stress of having to separate from a parent, these benefits may be at the emotional expense of the parents. Mater-

*This was noted before the preoperative fasting interval for children was shortened. nal upset is perceived accurately, paternal upset is hidden and difficult to appreciate. Despite the emotional expense, most parents report that, given the choice, they would choose to endure participating in their child's anaesthetic induction again. ${ }^{4,7,8}$ Nevertheless, parental upset should be-minimized, recognized, and acknowledged.

It should be noted that stress is not inherently bad and is normal in individuals experiencing potentially frightening situations. Mild stress helps individuals cope. However, when individuals become overtly upset, potential risks seem exaggerated and their fears are often verbally and nonverbally communicated to others. Such experiences can have a long-lasting impact on the individual and their family. ${ }^{12}$

The importance of parental upset is two-fold. First, because stress and upset are transferred between parent and child, ${ }^{5,13,14}$ an upset parent will more likely result in an upset child. ${ }^{15}$ Second, parents' negative perception of an emotional response to the anaesthesia experience may deleteriously affect their ability to cope with future surgical encounters for their children or themselves. Alternatively, a positive experience of participation in anaesthetic induction may serve as a "stress inoculation," - helpful to future encounters.

Although current practice allows children fluid intake until several hours before surgery, ${ }^{16}$ parents may also refrain from eating. The consequences of such behaviour is not known. On one hand, fasting with their children may be an effective way of adapting to the stress associated with the experience. However, the physiological consequences of fasting may amplify the stress experienced by parents. This may be a particular problem if surgery is scheduled later in the day or the family needs to travel a great distance on the morning of surgery. Perhaps during the pre-admission information session, parents should be encouraged to meet their own nutritional needs on the day of surgery and not fast with their child. This area warrants further study.

The seemingly comprehensive preoperative information session and tour conducted by the anaesthetist did not appear to prepare parents psychologically for participation in induction. While they were educated about what to expect, they were not told how they might cope with feelings that may occur during the induction process. Preparation for parents perhaps requires that information be provided to assist them in making the link between understanding what is going to happen in a given situation, and being able to handle it emotionally. ${ }^{17}$

Innovative approaches for preparing parents must be explored. For those who feel a lack of support (i.e., single parents), one approach would be to designate a specific health care volunteer or worker whose role would be to 
accompany parents preoperatively, during, and immediately after induction, ${ }^{18}$ to reassure them of their child's well-being. Alternatively, medical staff support could be provided at specific stress points, for example, when the child becomes upset before induction, or becomes limp during induction. ${ }^{19}$ Studies need to be conducted to validate methods for reducing the sense of helplessness experienced by parents in the face of their child's distress.

There is no substitute for common courtesy. Parental responses indicated that "staff rudeness" was upsetting. Although these reports were few, these reactions occurred primarily when staff members were discussing their personal lives and seemingly not concentrating on the care they were providing. The appearance of discourteous or brusque behaviour can undermine the effectiveness of any preparation programme that is used.

Ameliorating the experience of lack of control and its concomitant anxiety is more difficult. Parental lack of control is closely correlated to separation from their child but separation must occur before surgery. Parents are not likely, in the near future, to be granted more access to their children in the operating theatre than they currently enjoy. What is unclear, however, is what additional factors aside from separation lead to the parents' perceptions of not being in control. Some determinants that are liable to affect parental anxiety are: (1) whether preoperative medications are used, (2) previous experience with health care arenas, and (3) the climate of the overall environment. ${ }^{9.20}$ Moreover, the relationship of control to the timing of separation (i.e., prior to or following induction) is also not clear. Research has indicated that parents who have more latent (trait) anxiety do not fair as well as those with less latent anxiety ${ }^{5}$ and this will be an important variable to consider in future studies.

In conclusion, parental participation in the induction of anaesthesia for their child is a complex psychological experience. Recognizing the many factors associated with parental upset may help make parental participation a more positive experience for parents as well as their child.

\section{Acknowledgment}

The authors gratefully acknowledge the editorial assistance of Winifred von Ehrenburg and Rebecca Weber.

\section{References}

1 Roberts MC, Maier MJ, Collier J. Directory of hospital psychosocial policies and programs. Washington, DC: Association for the Care of Children's Health, 1988.

2 Hanallah RS, Rosales $J K$. Experience with parents' presence during araesthesia induction in children. Can Anaesth Soc J 1983; 30: 286-9.

3 Schulman $J L$, Foley JM, Vernon DTA, Allan D. A study of the effect of the mother's presence during anesthesia induction. Pediatrics 1967; 39: 111-4.

4 Smerling AJ, Lieberman I, Rothstein P. Parents' presence during induction of anesthesia in children: parents' viewpoint. Anesthesiology 1988; 69; A743.

5 Bevan JC, Johnston C, Haig MJ, et al. Preoperative parental anxiety predicts behavioral and emotional responses to induction of anaesthesia in children. Can $J$ Anaesth 1990; 37: 177-82.

6 Yemen TA, Nelson W. Parental presence at induction; do the parents make a difference? Anesthesiology 1992; 77: A1167.

7 Honig J, Maguire E, Hannallah $R$. Parent's response to observing anesthesia induction in their children. Anesthesiology 1991; 75: A1051.

8 Ryder IG, Spargo PM. Parents in the anaesthetic room. A questionnaire survey of parents' reactions. Anaesthesia 1991; 46: 977-9.

9 Braude $N$, Ridley SA, Sumner E. Parents and paediatric anacsthesia: a prospective survey of parental attitudes to their presence at induction. Ann R Coll Surg Engl 1990; 72: 41-4.

10 Cronenwett $L R$, Newmark $L L$. Fathers' responses to childbirth. Nurs Res 1974; 23: 210-7.

11 May KA. The father as observer. MCN Am J Matern Child Nurs 1982; 7: 319-22.

12 Lazarus RS, Folkman S. Stress, Appraisal, and Coping. New York: Springer Publishing Co., 1984.

13 Bush JP, Melamed BG, Sheras PL, Greensbaum $P E$. Mother-child patterns of coping with anticipatory medical stress. Health Psychol 1986; 5: 137-57.

14 Skipper JK, Leonard $R C$. Children, stress, and hospitalization: a field experiment. J Health Soc Behav 1968; 9 : 275-87.

15 Brophy CJ, Erickson MT. Children's self-statements and adjustment to elective outpatient surgery. J Dev Behav Pediatr 1990; 11: 13-6.

16 Schreiner MS, Thiebwasser $A$, Keon $T P$. Ingestion of liquids compared with preoperative fasting in pediatric outpatients. Anesthesiology 1990; 72: 593-7.

17 Vessey JA, Caserza CL, Bogetz MS. Another Pandora's Box? Parental participation in anesthetic induction. Child Health Care 1990; 19: 116-8.

18 Rigg JRA, Dunn GL, Gordon GS. Paediatric outpatient surgery under general anaesthesia. Anaesth Intensive Care 1980; 8: 451-3.

19 Visintainer MA, Wolfer JA. Psychological preparation for surgical pediatric patients: the effects on children's and parents' stress responses and adjustment. Pediatrics 1975; 56: 187-202.

20 Mc Gill WA, Hannallah RS. Parental presence during induction of anesthesia in children. Seminars in Anesthesia 1992; 11: 259-64. 